\title{
Anesthesia and postoperative analgesia during unilateral lower-extremity fracture surgeries using multiple injections through catheters beside the lumbar plexus or sciatic nerve
}

\author{
This article was published in the following Dove Press journal: \\ Therapeutics and Clinical Risk Management \\ 22 July 2013 \\ Number of times this article has been viewed
}

\author{
Xuezheng Zhang' \\ Ying Zhou' \\ Limei Chen' \\ Quanguang Wang' \\ Jianwu $\mathrm{Ni}^{\prime}$ \\ Le Liu' \\ Chenggang $\mathrm{Hu}^{2}$ \\ Xuzhong Xu' \\ 'Department of Anesthesiology, \\ First Affiliated Hospital of Wenzhou \\ Medical College, Wenzhou, Zhejiang, \\ People's Republic of China; \\ ${ }^{2}$ Department of Anesthesia, Pomerado \\ Hospital, Poway, CA, USA
}

Correspondence: Xuzhong Xu Department of Anesthesiology, First Affiliated Hospital of Wenzhou Medical College, 2 Fuxue Road, Wenzhou, Zhejiang 325000, People's Republic of China Tel +8657788069790 Email xuzhong_xu@।63.com
Objective: To compare the clinical effects of anesthesia and postoperative analgesia for patients with unilateral lower-extremity fracture between multiple injections through catheters beside the lumbar plexus or sciatic nerve and continuous epidural analgesia.

Methods: Seventy patients with unilateral lower-extremity fracture scheduled for internal fixation were randomly divided into group $\mathrm{N}(\mathrm{n}=35)$ and group $\mathrm{E}(\mathrm{n}=35)$. Patients in group $\mathrm{N}$ received combined lumbar plexus and sciatic nerve block, then a catheter was inserted into the psoas compartment or beside the sciatic nerve, according to the surgical site, and $25 \mathrm{~mL} 0.375 \%$ ropivacaine was injected into patients in group $\mathrm{N}$ through the peripheral nerve catheter 12 hours after operation. Patients in group E received combined spinal and epidural anesthesia, and when the operation was complete kept the epidural catheter and received patient-controlled epidural analgesia with an analgesia pump.

Results: The visual analog scores of patients at each time point in the two groups showed no significant difference $(P>0.05)$. Mean arterial pressure at 30 minutes after anesthesia and 4 hours postoperation in group $\mathrm{E}$ decreased significantly and was significantly lower than group $\mathrm{N}(P<0.01)$. Group $\mathrm{E}$ had significantly higher rate of urinary retention than group $\mathrm{N}$ $(P<0.05)$, and the time of first food intake of patients in group $\mathrm{N}$ was significantly shorter than in group $\mathrm{E}(P<0.001)$.

Conclusion: For patients with unilateral lower-extremity fracture receiving internal fixation, multiple injections through catheters beside the lumbar plexus or sciatic nerve can provide adequate postoperative analgesia, with very few adverse effects.

Keywords: lumbar plexus, sciatic nerve, catheterization, lower extremity, analgesia

\section{Introduction}

Lower-extremity fractures are common in orthopedic surgery, and are often treated with spinal anesthesia for surgical anesthesia as well as postoperative epidural analgesia. However, complications include urinary retention, delayed anal exhaust, nausea, and vomiting. Additionally there are risks for hypotension, respiratory inhibition, neurological damage, and epidural hematoma. ${ }^{1}$ One solution is peripheral blocking, which causes less disruption to the circulation as well as fewer complications. ${ }^{2,3}$ The present study aimed to compare the clinical effects of anesthesia and postoperative analgesia for patients with unilateral lower-extremity fracture between multiple injections through catheters beside the lumbar plexus or sciatic nerve and continuous epidural analgesia. 


\section{Materials and methods Clinical data}

Seventy patients with unilateral lower-extremity fractures were recruited for the study (46 males and 24 females, American Society of Anesthesiologists level I-II, age 19-74 years, weight $42-72 \mathrm{~kg}$, height $152-181 \mathrm{~cm}$ ). There were no patients with peripheral nervous system diseases, local anesthetic allergy history, or long-term use of opioids or nonsteroidal anti-inflammatory drugs. The study was approved by the local ethics committee of medical research on human subjects, and written consent from all patients was obtained.

\section{Surgery}

After overnight fasting for food and water, all patients were sedated with a $0.5-1 \mathrm{~mL}$ mixture of sedative (midazolam $5 \mathrm{mg}$ and fentanyl $0.1 \mathrm{mg}$ for $5 \mathrm{~mL}$ mixture). Mean artery pressure (MAP), heart rate (HR), and respiratory rate (RR) were monitored.

The patients were randomly assigned into two groups: the lumbar plexus/sciatic nerve block + catheter postoperative analgesia group $(\mathrm{N})$, and the spinal and epidural anesthesia + epidural controlled analgesia group (E), with 35 patients each.

In the $\mathrm{N}$ group, peripheral nerve block was performed with a MultiStim Switch nerve stimulator (Pajunk, Geisingen, Germany). For the sciatic nerve, $10 \mathrm{~mL} 0.75 \%$ ropivacaine mixed with $10 \mathrm{~mL} 2 \%$ lidocaine; for the lumbar plexus, $30 \mathrm{~mL} 0.5 \%$ ropivacaine. In the E group, $3 \mathrm{~mL} 0.5 \%$ bupivacaine solution (prepared by $2 \mathrm{~mL} 0.75 \%$ bupivacaine and $1 \mathrm{~mL} 10 \%$ glucose solution).

\section{Postoperative analgesia}

For postoperative analgesia, both $\mathrm{N}$ and $\mathrm{E}$ group patients received preoperative administration of $40 \mathrm{mg}$ parecoxib intravenously. Parecoxib $40 \mathrm{mg}$ was given on the night after the operation, followed by administration every 12 hours. In the $\mathrm{N}$ group, $25 \mathrm{~mL} 0.375 \%$ ropivacaine was given every 12 hours after the operation, followed by 30 minutes observation after each injection. In the E group, the analgesia pump was given for self-control (200 mL 0.15\% ropivacaine containing $3 \mathrm{mg}$ morphine, background flow rate $5 \mathrm{~mL} /$ hour, addition amount $2 \mathrm{~mL}$ with lock time of 15 minutes). For patients reporting incomplete analgesia (resting visual analog scale [VAS] score more than 3 ), $50 \mathrm{mg}$ pethidine intramuscular injection was given.

\section{Measurements}

Pain-intensity scores at 30 and 60 minutes after anesthesia, end of surgery, and 4, 8, 12, 24, and 48 hours later were evaluated with VAS (0-10), including resting VAS and motion VAS (active/subjective knee movement). MAP, HR, and RR values at 30 and 60 minutes after anesthesia, end of surgery, and 4, 8, 12,24 , and 48 hours later were monitored. The starting time point of food intake after surgery and complications within 48 hours after surgery were recorded (vomiting, itching, and urine retention). Satisfaction scores for the surgery were evaluated by patients ( $0-5$ from unsatisfied to very satisfied).

\section{Statistics}

Data were processed with Stata 7.0 software (StataCorp LP, College Station, TX, USA); $\alpha=0.05,1-\beta=0.8$. Comparisons between groups were done with $t$-tests. Complications and satisfaction scores were compared with the Chi-squared test. $P<0.05$ was determined as statistically significant.

\section{Results}

We found no differences in sex, age, height, or weight between the two groups $(P>0.05$, Table 1). All patients showed satisfactory anesthesia, and the surgeries were completed successfully.

\section{Analgesia results}

In the $\mathrm{N}$ group 17 cases were with sciatic nerve catheter and 18 cases were with lumbar plexus catheter analgesia. In both $\mathrm{N}$ and $\mathrm{E}$ groups, postoperative analgesia was satisfactory and no pethidine was used. VAS scores (both resting and motion) were low, without differences across groups $(P>0.05$, Table 2$)$.

\section{Vital signs}

MAP, HR, and RR are shown in Table 2. In the $\mathrm{N}$ group, postoperative MAP, HR, and RR values did not change compared to basal values $(P>0.05)$. In the $\mathrm{E}$ and $\mathrm{N}$ groups, the MAP value was lower than the basal value 30 minutes after anesthesia and 4 hours after surgery $(P<0.01)$.

\section{Complications}

The $\mathrm{N}$ group showed a lower rate of urinary retention than the $\mathrm{E}$ group (one case for N, 24 cases for E; $P<0.001$ ), less nausea

Table I Clinical data for the two groups of patients $(n=30)$

\begin{tabular}{llllll}
\hline Group & $\begin{array}{l}\text { ASA grade } \\
(\mathrm{I} / \mathrm{II})\end{array}$ & $\begin{array}{l}\text { Sex } \\
(\mathrm{m} / \mathrm{f})\end{array}$ & $\begin{array}{l}\text { Age } \pm \text { SD } \\
(\text { years })\end{array}$ & $\begin{array}{l}\text { Weight } \\
(\mathbf{k g})\end{array}$ & $\begin{array}{l}\text { Height } \\
(\mathbf{c m})\end{array}$ \\
\hline $\mathrm{N}$ & $22 / 13$ & $24 / 1 \mathrm{I}$ & $50 \pm 16$ & $6 \mathrm{I} \pm 1 \mathrm{II}$ & $168 \pm 6$ \\
$\mathrm{E}$ & $25 / 10$ & $23 / 12$ & $49 \pm 15$ & $60 \pm 8$ & $167 \pm 5$ \\
\hline
\end{tabular}

Notes: $\mathrm{N}$, the lumbar plexus/sciatic nerve block + catheter postoperative analgesia group; E, the spinal and epidural anesthesia + epidural controlled analgesia group. Abbreviations: ASA, American Society of Anesthesiologists; m, male; f, female; $\mathrm{SD}$, standard deviation. 
Table 2 Main artery pressure (MAP), heart rate (HR), respiratory rate (RR), and visual analog scale (VAS) scores in the two groups of patients ( $n=35$ each)

\begin{tabular}{|c|c|c|c|c|c|c|c|c|c|c|}
\hline & Group & $\begin{array}{l}\text { Basal } \\
\text { (mean } \pm \text { SD) }\end{array}$ & $\begin{array}{l}30 \text { minutes } \\
\text { after } A\end{array}$ & $\begin{array}{l}60 \text { minutes } \\
\text { after } A\end{array}$ & $\begin{array}{l}\text { End of } \\
\text { surgery }\end{array}$ & $\begin{array}{l}4 \text { hours } \\
\text { after } 0\end{array}$ & $\begin{array}{l}8 \text { hours } \\
\text { after } 0\end{array}$ & $\begin{array}{l}12 \text { hours } \\
\text { after } 0\end{array}$ & $\begin{array}{l}24 \text { hours } \\
\text { after } 0\end{array}$ & $\begin{array}{l}48 \text { hours } \\
\text { after } 0\end{array}$ \\
\hline MAP & $N$ & $91 \pm 8$ & $90 \pm 9$ & $90 \pm 8$ & $90 \pm 8$ & $92 \pm 9$ & $90 \pm 13$ & $89 \pm 8$ & $91 \pm 9$ & $89 \pm 10$ \\
\hline$(\mathrm{mmHg})$ & E & $90 \pm 9$ & $81 \pm 8^{\#, * *}$ & $88 \pm 9$ & $87 \pm 9$ & $86 \pm 11^{* *}$ & $88 \pm 8$ & $86 \pm 13$ & $87 \pm 11$ & $89 \pm 8$ \\
\hline$H R$ & $\mathrm{~N}$ & $79 \pm 10$ & $76 \pm 11$ & $75 \pm 13$ & $76 \pm 10$ & $79 \pm 11$ & $75 \pm 10$ & $76 \pm 10$ & $77 \pm 11$ & $78 \pm 11$ \\
\hline (/minute) & E & $78 \pm 8$ & $74 \pm 9$ & $74 \pm 9$ & $77 \pm 11$ & $77 \pm 9$ & $78 \pm 10$ & $76 \pm 11$ & $78 \pm 13$ & $78 \pm 11$ \\
\hline RR & $N$ & $19.6 \pm 1.8$ & $19.4 \pm 1.8$ & $18.4 \pm 2.5$ & $18.7 \pm 2.8$ & $19.4 \pm 1.7$ & $19.4 \pm 1.8$ & $19.5 \pm 1.7$ & $19.6 \pm 1.9$ & $19.3 \pm 1.8$ \\
\hline (/minute) & E & $19.8 \pm 1.9$ & $19.2 \pm 1.6$ & $18.8 \pm 1.6$ & $19.5 \pm 2.6$ & $18.5 \pm 1.7$ & $18.9 \pm 1.7$ & $19.3 \pm 1.6$ & $19.4 \pm 1.6$ & $19.5 \pm 1.8$ \\
\hline Resting & $\mathrm{N}$ & - & 0 & 0 & 0 & $0.23 \pm 0.47$ & $0.38 \pm 0.58$ & $0.43 \pm 0.59$ & $1.15 \pm 0.63$ & $0.77 \pm 0.60$ \\
\hline VAS & E & - & 0 & 0 & 0 & $0.45 \pm 0.78$ & $0.56 \pm 0.44$ & $0.58 \pm 0.50$ & $1.13 \pm 0.67$ & $0.56 \pm 0.57$ \\
\hline Motion & $\mathrm{N}$ & - & 0 & 0 & 0 & $0.53 \pm 0.62$ & $0.88 \pm 0.65$ & $1.23 \pm 0.72$ & $1.25 \pm 0.68$ & $1.23 \pm 0.53$ \\
\hline VAS & E & - & 0 & 0 & 0 & $0.57 \pm 0.61$ & $0.93 \pm 0.65$ & $1.25 \pm 0.72$ & $1.25 \pm 0.68$ & $1.27 \pm 0.64$ \\
\hline
\end{tabular}

Notes: $P<0.0$ l compared to basal condition; $* * P<0.01$ compared to the $\mathrm{N}$ group; $\mathrm{N}$, the lumbar plexus/sciatic nerve block + catheter postoperative analgesia group; $\mathrm{E}$, the spinal and epidural anesthesia + epidural controlled analgesia group.

Abbreviations: A, anesthesia; O, operation; SD, standard deviation.

and vomiting (no cases for $\mathrm{N}$, eight cases for $\mathrm{E} ; P<0.001$ ), less itching (no cases for $\mathrm{N}$, ten cases for $\mathrm{E} ; P<0.001$ ), and shorter time to restart food intake (1.2 \pm 1.1 hours for $\mathrm{N}$, $6.9 \pm 0.8$ hours for $\mathrm{E} ; P<0.001)$. Satisfaction percentages were $96.7 \%$ for $\mathrm{N}$ and $90 \%$ for $\mathrm{E}(P=0.6)$.

\section{Discussion}

Perioperative pain in patients with fractures is associated with fear, suffering, and increased medical care/costs. ${ }^{1,4,5}$ The management of such surgeries with spinal anesthesia and/or epidural anesthesia brings certain clinical effects, as well as different complications. ${ }^{1}$ On the contrary, lumbar plexus/ sciatic nerve block is limited to the lower limb on the affected side, with little interference to the circulation system, and therefore is hemodynamically stable. ${ }^{2}$ It will be important to compare the use of the two different approaches in clinical practice to achieve better treatment and clinical care.

In the present study, we found similar anesthetic and postoperative analgesic effects with peripheral nerve block, compared to the spinal anesthesia approach. Additionally, the peripheral nerve-block approach was associated with fewer complications. The blocking effects with a single injection diminished in 12 hours, ${ }^{6}$ while the catheter technique can be left for a week in order to maintain the perfusion of local anesthetics when necessary. This could be done with continuous perfusion through a pump (8-12 mL/hour), ${ }^{7}$ which sometimes led to overdose and toxicity. ${ }^{8}$ In our case, we employed a multiple-injection protocol, ${ }^{9}$ which significantly extended the pharmacological effects without adverse events being observed.

In summary, catheter-mediated peripheral nerve-block anesthesia and postoperative analgesia for lower-limb unilateral fractures demonstrated similar clinical effects of continuous epidural analgesia, and had fewer complications.

\section{Acknowledgments}

This study was supported by the Department of Science and Technology of Wenzhou (H0090013), Zhejiang, People's Republic of China.

\section{Disclosure}

The authors report no conflicts of interest in this work.

\section{References}

1. Chelly JE, Ben-David B, Williams BA, Kentor ML. Anesthesia and postoperative analgesia: outcomes following orthopedic surgery. Orthopedics. 2003;26(Suppl 8):s865-s871.

2. Enneking FK, Chan V, Greger J, Hadzić A, Lang SA, Horlocker TT. Lower-extremity peripheral nerve blockade: essentials of our current understanding. Reg Anesth Pain Med. 2005;30(1):4-35.

3. Navas AM, Gutierrez TV, Moreno ME. Continuous peripheral nerve blockade in lower extremity surgery. Acta Anaesthesiol Scand. 2005;49(8):1048-1055.

4. Schroeder K, Andrei AC, Furlong MJ, Donnelly MJ, Han S, Becker AM. The perioperative effect of increased body mass index on peripheral nerve blockade: an analysis of 528 ultrasound guided interscalene blocks. Rev Bras Anestesiol. 2012;62(1):28-38.

5. Fowler SJ, Symons J, Sabato S, Myles PS. Epidural analgesia compared with peripheral nerve blockade after major knee surgery: a systematic review and meta-analysis of randomized trials. Br J Anaesth. 2008;100(2):154-164.

6. Biboulet P, Morau D, Aubas P, Bringuier-Branchereau S, Capdevila X. Postoperative analgesia after total-hip arthroplasty: comparison of intravenous patient-controlled analgesia with morphine and single injection of femoral nerve or psoas compartment block. A prospective, randomized, double-blind study. Reg Anesth Pain Med. 2004;29(2): 102-109.

7. Campbell A, McCormick M, McKinlay K, Scott NB. Epidural vs lumbar plexus infusions following total knee arthroplasty: randomized controlled trial. Eur J Anaesthesiol. 2008;25(6):502-507.

8. Kaloul I, Guay J, Cote C, Halwagi A, Varin F. Ropivacaine plasma concentrations are similar during continuous lumbar plexus blockade using the anterior three-in-one and the posterior psoas compartment techniques. Can J Anaesth. 2004;51(1):52-56.

9. Vanterpool S, Steele SM, Nielsen KC, Tucker M, Klein SM. Combined lumbar-plexus and sciatic-nerve blocks: an analysis of plasma ropivacaine concentrations. Reg Anesth Pain Med. 2006;31(5):417-421. 
Therapeutics and Clinical Risk Management

Dovepress

\section{Publish your work in this journal}

Therapeutics and Clinical Risk Management is an international, peerreviewed journal of clinical therapeutics and risk management, focusing on concise rapid reporting of clinical studies in all therapeutic areas, outcomes, safety, and programs for the effective, safe, and sustained use of medicines. This journal is indexed on PubMed Central, CAS,

EMBase, Scopus and the Elsevier Bibliographic databases. The manuscript management system is completely online and includes a very quick and fair peer-review system, which is all easy to use. Visit http://www.dovepress.com/testimonials.php to read real quotes from published authors.

Submit your manuscript here: http://www.dovepress.com/therapeutics-and-clinical-risk-management-journal 